\title{
Diet, Breakfast, and Academic Performance in Children
}

\author{
R.E. Kleinman ${ }^{a} \quad$ S. Hall ${ }^{b} \quad$ H. Greenc $\quad$ D. Korzec-Ramirez ${ }^{d} \quad$ K. Patton ${ }^{b}$ \\ M.E. Paganoe J .M. Murphy ${ }^{f}$
}

a Massachusetts General Hospital, Division of Pediatric Gastroenterology and Nutrition and Harvard Medical School, Department of Pediatrics, Boston, Mass.; bMassachusetts General Hospital, Department of Psychiatry, Boston, Mass.; ' Formerly of Project Bread/The Walk for Hunger, Boston, Mass.; ${ }^{\mathrm{d} D e p a r t m e n t}$ of Food and Nutrition Services, Boston Public Schools, Boston, Mass.; ${ }^{B}$ Brown University, Department of Psychiatry and Human Behavior, Providence, R.I., and fMassachusetts General Hospital, Child Psychiatry Service and Harvard Medical School, Department of Psychiatry, Boston, Mass., USA

\section{Key Words}

School breakfast - Low-income children · Psychosocial functioning $\cdot$ Nutrition - Dietary intake

\begin{abstract}
Objective: To determine whether nutrient intake and academic and psychosocial functioning improve after the start of a universal-free school breakfast program (USBP). Methods: Information was gathered from 97 inner city students prior to the start of a USBP and again after the program had been in place for 6 months. Students who had total energy intakes of $<50 \%$ of the recommended daily allowance (RDA) and/or 2 or more micronutrients of $<50 \%$ of RDA were considered to be at nutritional risk. Results: Prior to the USBP, 33\% of all study children were classified as being at nutritional risk. Children who were at nutritional risk had significantly poorer attendance, punctuality, and grades at school, more behavior problems, and were less likely to eat breakfast at school than children who were not at nutritional risk. Six months after the start of the free school breakfast programs, students who decreased their nutri-
\end{abstract}

\section{KARGER}

Fax +41613061234

E-Mail karger@karger.ch

www. karger.com
(C) 2002 S. Karger AG, Basel

0250-6807/02/0467-0024\$18.50/0

Accessible online at:

www. karger.com/anm tional risk showed significantly greater: improvements in attendance and school breakfast participation, decreases in hunger, and improvements in math grades and behavior than children who did not decrease their nutritional risk. Conclusion: Participation in a school breakfast program enhanced daily nutrient intake and improvements in nutrient intake were associated with significant improvements in student academic performance and psychosocial functioning and decreases in hunger.

Copyright $\odot 2002$ S. Karger AG, Basel

Over the past few decades, it has become clear that many children in the USA experience chronic mild-tomoderate food deprivation, defined as food insufficiency and/or hunger. A recent survey conducted by the US Department of Agriculture [1] reported the prevalence of hunger/food insufficiency among children in the USA to be $18 \%$, even during a period of remarkable overall financial prosperity for the country as a whole. In recent reports, we have explored the relationship between hunger and academic and psychosocial functioning during childhood [2, 3] and demonstrated that children whose 
parents reported hunger/food insufficiency were more likely to have repeated a grade in school, received special education and/or mental health counseling, to have gotten lower scores on tests of psychological adjustment, lower grades in math, and to have had more days tardy and absent from school.

Despite the consistent and inverse relationship between hunger and child functioning, the nutritional correlates of this association remain largely unexplored. In one of the few studies to date [Kleinman et al., unpubl. data], about one third of inner city public school children had low caloric intakes and/or low intakes of selected micronutrients. These children were significantly more likely to report hunger and had significantly worse grades in school, higher rates of absenteeism, and more psychological problems in comparison to children with more adequate dietary intakes. A recent study by another group was based on a large and nationally representative sample and documented the link between hunger/food insufficiency and health problems during childhood [4].

One way to combat problems associated with child hunger would be to augment an existing governmental food program. Previous studies by our group have shown that it is possible to increase participation in the school breakfast program by making it universally free to all students and that students who increase their school breakfast participation [5] show significant gains in academic and psychosocial functioning as well as decreased hunger. However, despite the documented benefits of school breakfast programs in terms of reducing hunger and improving child psychosocial functioning, the nutritional benefits of these programs remain unclear, as does the link between improvements in nutritional status and improvements in academic and behavioral functioning.

Previous studies have shown that failure to eat breakfast or lack of nutritious food for breakfast is common in childhood [6] and may increase the risk of being undernourished. Several studies have suggested a significant relationship between skipping breakfast and low nutrient intakes in children [6-9]. In the current study, we assessed the relationship between child nutritional risk status, hunger, participation in a school breakfast program, academic performance, and psychosocial functioning.

\section{Methods}

Data for the current analyses came from a collaborative study of a universal-free school breakfast program (USBP) in the Boston Public Schools. Children and their parents in three inner city schools were recruited for this study, prior to the implementation of the USBP.
The parents of all 227 students in grades 4 through 6 of these schools were invited to participate in the study through letters that were sent home with students, and only 1 child per family was eligible. One hundred forty-nine $(66 \%)$ students returned permission slips from parents indicating a willingness to participate in the study.

When interviews were scheduled, 50 of these parents were unavailable to be interviewed, leaving a sample of 99 families $(66 \%$ of the 149 consenting students and $44 \%$ of the initial cohort of 227 students). Children were re-interviewed approximately 6 months after the implementation of the USBP. Of the 99 families who had completed the initial interview, $1(1 \%)$ had moved out of town, and 1 $(1 \%)$ was unable to complete the re-interview, leaving a final sample of 97 subjects with complete pre- and post-USBP parent/student interviews.

The study was approved by the Subcommittee on Human Studies at the Massachusetts General Hospital, Boston (IRB\#1999P006455), and by the research committee of the Boston Public Schools. Participation by parents and children was voluntary and access to school records was made possible through separate consent forms signed by parents and children.

The children's gender, age, ethnicity, and parental marital status were assessed from a questionnaire administered during the initial interview with parents. A validated 24-hour dietary recall method using standardized graduated food models was adapted for use in interviewing children $[10,11]$. A single 24-hour dietary recall was collected on each study participant before and 6 months after the start of the USBP and was analyzed using the Minnesota Nutritional Data System software version 2.3. The dietary recall period reflected the previous $24 \mathrm{~h}$. For the purposes of this study, dietary intake was evaluated as the percent of RDA for age and gender for specific nutrients and energy [12].

The total daily energy intake of each child was assessed at the initial interview and was compared with the RDA for age and gender [12]. Children were considered to consume a low-energy diet if their total daily energy intake was $\leq 50 \%$ of the RDA. Because several national studies have shown that children in the USA consume substantially less than the recommended daily amounts of vitamins A, $\mathrm{B}_{6}, \mathrm{~B}_{12}, \mathrm{C}$, and folate, iron, zinc, and calcium [13], the intake of these 8 micronutrients was assessed from the 24-hour recall and compared with the RDAs. Although other investigators have explored using a cut-off of $\leq 67 \%$ of RDA as a standard for low nutrient intake [14], we adopted a somewhat more stringent standard and considered an intake of a particular nutrient as low if the daily nutrient consumption was $\leq 50 \%$ of the RDA.

Children who consumed two or more nutrients at $\leq 50 \%$ of the RDA and/or who had an energy intake of $\leq 50 \%$ RDA were aggregated into a low nutrient intake group for the purpose of examining relationships between nutrient intake and other outcome variables. Children who did not meet these criteria for low nutrient intake were considered to have adequate nutrient intakes for the purposes of the study.

School breakfast participation was coded from official school food service records at the schools. For each student, food service staff provided data on daily participation for 1 week prior to the start of the USBP, and another week, after the USBP had been running for approximately 6 months. Data on each student's daily school attendance was also collected for the same 1-week periods to permit the calculation of a school breakfast participation rate (number of days eating school breakfast divided by number of days present; range from 0 to $100 \%$ ). Children were considered to participate 'often' if 
they ate breakfast $80 \%$ or more of days present, to participate 'sometimes' if they ate between 20 and $79 \%$ of days present, and to participate 'rarely' if they ate breakfast in school $<20 \%$ of the time.

Parents completed an 8-item hunger/food insufficiency questionnaire developed by the Community Childhood Hunger Identification Project (CCHIP) $[15,16]$ at the time of the interviews. Children were classified as 'hungry' if the parent responded positively to 5 or more of the 8 questions concerning hunger in the past year. Children were classified as 'at risk for hunger' if the parent responded positively to one or as many as 4 of the 8 food insufficiency questions. If the parent did not respond positively to any of the 8 food insufficiency questions, the household and child were classified as 'not hungry'. Parents were only interviewed in the fall, so on the Parent CCHIP form, only pretest data are available.

Children were asked to fill out a 5-item version of the CCHIP survey, the Child Hunger Index Child Report (CHI-C), which has been shown to be a valid and reliable instrument to identify hunger by child report $[2,3]$. Children who responded positively to 2 or more of the CHI-C questions were classified as 'hungry'. When the child responded positively to one of the questions, the child was classified as 'at risk for hunger' on the CHI-C. Those who did not respond positively to any of the items were classified as 'not hungry'.

The Pediatric Symptom Checklist (PSC) [17] consists of 35 items that are reported 'never', 'sometimes', or 'often' present and scored 0 , 1 or 2, respectively. A total score is obtained by adding the scores for each of the items. For the PSC, higher scores indicate worse functioning. Also used in the study was the youth self-report version of the Pediatric Symptom Checklist (PSC-Y) [18, 19], which is scored the same way as the parent-completed form.

Official school records were reviewed to obtain student grades for Math, Reading, Science, and Social Studies and their absence and tardiness rates for the full 1998-1999 (pre-USBP) and 1999-2000 (post-USBP) school years. Letter grades were converted into numeric values based on a 4.0 grading system $(\mathrm{A}=4.0, \mathrm{~B}=3.0, \mathrm{C}=2.0, \mathrm{D}=$ $1.0, \mathrm{~F}=0.0$ ), and summed to generate an overall grade point average.

Because data on prior year academic performance for middle school students are kept in their original elementary schools, and it was not feasible to travel to each middle school student's elementary school to obtain his/her grades and attendance for the year prior to the first year of the school breakfast program, the year two and change data reported in this study for these variables concern only the 79 students who were in elementary school the year before the study began.

The goal of our data analyses was to examine the association between dietary intake and hunger, school breakfast participation, psychosocial functioning, and academic performance scores. Categorical group differences were examined using Pearson $\chi^{2}$ analysis, and continuous score differences among dietary intake groups were examined using one-way analysis of variance.

\section{Results}

The socioeconomic and ethnic characteristics of the children were similar in all three schools $(>70 \%$ of the children were eligible for free or reduced-price meals, and $>70 \%$ of the children were of African-American or His- panic descent). In the combined sample, approximately half of the children were male $(41 \% ; 40 / 97)$. Eighty-two percent $(80 / 97)$ were from elementary grades (3 through 5 ), and $18 \%$ (17/97) were from middle school (grade 6). Fifty-five percent (53/97) of the children were from single-parent families.

Twenty-nine percent (28/97) of the children had two or more nutrient intakes that were $\leq 50 \%$ of the RDA. Thirteen percent (13/97) of the children consumed $\leq 50 \%$ of the RDA for energy. Combining the two groups, 30\% (29/ 97) of these children consumed two or more of the micronutrients and/or a total energy intake of $\leq 50 \%$ of the RDA. Children in the low nutrient intake group did not differ significantly from their peers with respect to gender, grade, or parental marital status.

Data on low nutrient intake and child functioning prior to the start of the USBP are shown in table 1. Prior to the introduction of the USBP, $61 \%$ (59/97) of the children were classified as eating school breakfast rarely, $16 \%$ (15/97) as eating school breakfast sometimes, and 24\% (23/97) ate school breakfast often. Children who ate school breakfast rarely were significantly more likely $(41 \%)$ to be nutritionally at risk than were children who ate school breakfast sometimes $(7 \%)$ or often $\left(17 \% ; \chi^{2}=\right.$ 5.8 , d.f. $=2, \mathrm{p}<0.05)$.

According to the 8-item CCHIP scale, 72\% (70/97) of children were classified as not hungry, 19\% (18/97) were classified as at risk for hunger, and 9\% (9/97) were classified as hungry. Parent-reported child hunger on CCHIP was significantly associated with nutritional risk, with rates that were about five times higher in hungry and at risk for hunger children as in not-hungry children (56 and $72 \%$ vs. $16 \% ; \chi^{2}=24.9$, d.f. $\left.=2, p<0.0001\right)$. Average CCHIP scores also differed significantly according to nutritional status: children in the nutritional risk group had average hunger scores of 2.5 compared to children with adequate nutrient intakes who had an average hunger score of $0.6(\mathrm{~F}=18.6$, d.f. $=1, \mathrm{p}<0.0001)$.

Child report of hunger as measured by the CHI-C followed the same patterns as parent report of hunger. Fortyseven percent of CHI-C hungry children were at nutritional risk, as were $67 \%$ of the CHI-C at-risk children but only $19 \%$ of the not-hungry children, a difference that was also statistically significant $\left(\chi^{2}=13.9\right.$, d.f. $\left.=2, p<0.001\right)$. Average CHI-C scores also differed significantly according to nutritional status: children in the nutritional risk group had average hunger scores of 1.2 compared to children with adequate nutrient intakes who had an average hunger score of $0.5(\mathrm{~F}=5.0$, d.f. $=1, \mathrm{p}<0.05)$. 
Table 1. Child nutritional indicators and psychosocial functioning measures pre-USBP ${ }^{1}$

\begin{tabular}{|c|c|c|c|}
\hline & $\begin{array}{l}\text { Total } \\
\mathrm{n}(\%) \\
97(100)\end{array}$ & $\begin{array}{l}\text { Energy and } \\
\text { nutrient intake } \\
\text { adequate, n (\%) } \\
68(70)\end{array}$ & $\begin{array}{l}\text { Energy and/or 2+ } \\
\text { nutrients }<50 \% \\
\text { RDA low, n (\%) } \\
29(30)\end{array}$ \\
\hline \multicolumn{4}{|c|}{ School breakfast participation } \\
\hline Mean & $29.6(41.4)$ & $36.3(42.9)$ & $13.8(33.4)^{\mathrm{b}}$ \\
\hline Rarely & $59(61)$ & $35(59)$ & $24(41)$ \\
\hline Sometimes & $15(16)$ & $14(93)$ & $1(7)$ \\
\hline Often & $23(24)$ & $19(83)$ & $4(17)^{b}$ \\
\hline \multicolumn{4}{|l|}{ Parent report } \\
\hline CCHIP total score & $1.2(2.2)$ & $0.6(1.8)$ & $2.5(2.6)^{\mathrm{e}}$ \\
\hline Not hungry & $70(72)$ & $59(84)$ & $11(16)$ \\
\hline At risk & $18(19)$ & $5(28)$ & $13(72)$ \\
\hline Hungry & $9(9)$ & $4(44)$ & $5(56)^{\mathrm{e}}$ \\
\hline \multicolumn{4}{|l|}{ Child report } \\
\hline CHI-C total score & $0.7(1.4)$ & $0.5(1.3)$ & $1.2(1.5)^{\mathrm{a}}$ \\
\hline Not hungry & $68(70)$ & $55(81)$ & $13(19)$ \\
\hline At risk & $12(12)$ & $4(33)$ & $8(67)$ \\
\hline Hungry & $17(18)$ & $9(53)$ & $8(47)^{d}$ \\
\hline \multicolumn{4}{|l|}{ PSC parent report } \\
\hline Total score & $14.1(9.8)$ & $12.0(7.9)$ & $19.2(12.2)^{\mathrm{d}}$ \\
\hline PSC non-case & $87(91)$ & $67(77)$ & $20(23)$ \\
\hline PSC case & $9(9)$ & $1(11)$ & $8(89)^{d}$ \\
\hline \multicolumn{4}{|l|}{ PSC youth report } \\
\hline Total score & $19.8(9.9)$ & $18.5(9.0)$ & $22.7(11.3)^{\mathrm{a}}$ \\
\hline Non-case & $83(86)$ & $62(75)$ & $21(25)$ \\
\hline Case $^{\mathrm{b}}$ & $14(14)$ & $6(43)$ & $8(57)^{\mathrm{b}}$ \\
\hline \multicolumn{4}{|l|}{ School record measures } \\
\hline GPA & $2.6(0.8)$ & $2.8(0.7)$ & $2.1(0.8)^{\mathrm{d}}$ \\
\hline Reading & $2.5(0.9)$ & $2.6(0.8)$ & $1.9(0.9)^{\mathrm{c}}$ \\
\hline Math & $2.4(1.0)$ & $2.7(0.6)$ & $1.7(0.9)^{\mathrm{d}}$ \\
\hline Social studies & $2.7(0.7)$ & $2.6(0.8)$ & $2.3(0.9)^{\mathrm{c}}$ \\
\hline Science & $2.8(0.9)$ & $2.9(0.8)$ & $2.4(0.8)^{\mathrm{c}}$ \\
\hline Days absent & $7.8(7.7)$ & $6.5(5.4)$ & $11.5(11.3)^{\mathrm{b}}$ \\
\hline Days tardy & $2.9(5.2)$ & $1.9(3.0)$ & $5.7(8.2)^{\mathrm{b}}$ \\
\hline
\end{tabular}

${ }^{\mathrm{a}} \mathrm{p}<0.10 ;{ }^{\mathrm{b}} \mathrm{p}<0.05 ;{ }^{\mathrm{c}} \mathrm{p}<0.01 ;{ }^{\mathrm{d}} \mathrm{p}<0.001 ;{ }^{\mathrm{e}} \mathrm{p}<0.0001$.

1 Mean school breakfast participation: number of days eating school breakfast divided by days attended.
Children who were nutritionally at risk had significantly higher PSC mean scores than those who were not at nutritional risk $(19.2$ vs. $12.0 ; \mathrm{F}=11.6$, d.f. $=1, \mathrm{p}<$ 0.001). Similarly, children who were nutritionally at risk had a mean PSC-Y score of 22.7 and those who were not at nutritional risk had a mean PSC-Y score of 18.5, a difference that was marginally statistically significant $(\mathrm{F}=$ 3.7, d.f. $=2, \mathrm{p}<0.10$ )

Diet, Breakfast, and Academic Performance in Children
The mean grade point average (GPA) of the children for the full year prior to the introduction of the USBP was $2.6(\mathrm{SD}=0.8)$. Children with low nutritional intakes had a significantly lower GPA $(\mathrm{M}=2.1)$ than children with adequate intakes of both nutrients and energy $(\mathrm{M}=2.8 ; \mathrm{F}=$ 8.5 , d.f. $=2, \mathrm{p}<0.001)$. The same pattern was observed in each of the four subject areas (Reading, Math, Social Studies, and Science): with statistically significant differences of between one half and one full letter grade be-

Ann Nutr Metab 2002;46(suppl 1):24-30 
Table 2. Changes in nutritional risk and child outcome measures post-USBP ${ }^{1}$

\begin{tabular}{|c|c|c|c|c|}
\hline & \multicolumn{4}{|c|}{ Nutritional Status } \\
\hline & $\begin{array}{l}\text { Total } \\
\text { n (\%) } \\
97(100 \%)\end{array}$ & $\begin{array}{l}\text { Worse } \\
\mathrm{n}(\%) \\
17(18)\end{array}$ & $\begin{array}{l}\text { No change } \\
\text { n (\%) } \\
62(64)\end{array}$ & $\begin{array}{l}\text { Improved } \\
\mathrm{n}(\%) \\
18(19)\end{array}$ \\
\hline \multicolumn{5}{|l|}{ Categorical change in school breakfast } \\
\hline Decrease in breakfast rate & $19(20)$ & $8(42)$ & $11(58)$ & $0(0)$ \\
\hline No change in breakfast rate & $34(35)$ & $5(15)$ & $25(74)$ & $4(12)$ \\
\hline Increase in breakfast rate & $44(45)$ & $4(9)$ & $26(59)$ & $14(32)^{c}$ \\
\hline Mean change in school breakfast rate (SD) & $21.3(52.0)$ & $-11.0(59.5)$ & $20.2(47.6)$ & $+55.8(38.8)^{\mathrm{b}}$ \\
\hline \multicolumn{5}{|l|}{ Hunger } \\
\hline CHI-C mean hunger score change & $-0.3(1.2)$ & $+0.3(1.0)$ & $-0.2(0.9)$ & $-1.4(1.5)^{\mathrm{d}}$ \\
\hline \multicolumn{5}{|l|}{ PSC } \\
\hline Youth report change & $-1.5(7.3)$ & $+1.9(5.9)$ & $-2.0(7.4)$ & $-3.2(7.6)^{\mathrm{c}}$ \\
\hline \multicolumn{5}{|l|}{ School record measures } \\
\hline Overall GPA change mean (SD) & $-0.1(0.5)$ & $-0.1(0.4)$ & $-0.1(0.4)$ & $0.0(0.8)$ \\
\hline Reading & $-0.2(0.8)$ & $-0.2(0.6)$ & $-0.2(0.5)$ & $-0.3(1.3)$ \\
\hline Math & $+0.2(0.8)$ & $+0.0(1.1)$ & $+0.1(0.7)$ & $+0.6(0.6)^{\mathrm{b}}$ \\
\hline Social studies & $-0.3(0.8)$ & $-0.3(0.6)$ & $-0.2(0.5)$ & $-0.3(1.3)$ \\
\hline Science & $-0.1(0.8)$ & $0.0(0.9)$ & $-0.1(0.7)$ & $+0.1(1.0)$ \\
\hline $\begin{array}{l}\text { Days absent } \\
\text { Days tardy }\end{array}$ & $\begin{array}{l}-1.3(5.9) \\
+0.1(6.2)\end{array}$ & $\begin{array}{l}+3.0(4.7) \\
+2.2(4.9)\end{array}$ & $\begin{array}{l}-1.7(6.0) \\
-0.3(6.5)\end{array}$ & $\begin{array}{l}-4.4(4.6)^{\mathrm{c}} \\
-2.7(5.4)\end{array}$ \\
\hline
\end{tabular}

${ }^{\mathrm{a}} \mathrm{p}<0.10 ;{ }^{\mathrm{b}} \mathrm{p}<0.05 ;{ }^{\mathrm{c}} \mathrm{p}<0.01 ;{ }^{\mathrm{d}} \mathrm{p}<0.001 ;{ }^{\mathrm{e}} \mathrm{p}<0.0001$.

1 Mean school breakfast participation: number of days eating school breakfast divided by days attended.

tween nutritionally at-risk children and those who were not at risk.

Prior to the implementation of USBP, children who were not at nutritional risk had an absence rate of 6.5 days, and those who were nutritionally at risk had an absence rate of 11.5 days, a difference that was statistically significant $(F=3.7$, d.f. $=1, p<0.05)$. Children who were not at nutritional risk prior to the start of the USBP had been tardy an average of 1.9 days during the previous school year, whereas children who were at nutritional risk were tardy 5.7 days the year before, a difference that was also statistically significant $(\mathrm{F}=3.6$, d.f. $=1, \mathrm{p}<0.05)$.

Approximately 6 months following the implementation of the USBP the same measures were used when students were re-interviewed and their records for the year that USBP started were compared with the same academic indicators for the year before the program. For each of these variables the change from pre-USBP to post-USBP were calculated. These changes were examined in the light of changes in nutritional risk.
Data collected 6 months following implementation of the USBP are shown in table 2. Changes in nutritional risk were calculated by subtracting the pre-USBP nutritional risk score (low intake of both, either, or neither energy nor micronutrients; coded 2,1 , or 0 ) from the postUSBP nutritional risk score (coded the same way), so that children could be rated as improved, the same, or worse. Six months after implementing the USBP, $19 \%$ of the sample were coded as having improved their nutrient intake, $64 \%$ of the sample were unchanged, and $18 \%$ were at increased nutritional risk.

Children whose nutritional status improved showed significantly larger increases in school breakfast participation than children whose nutritional status stayed the same or worsened (average school breakfast participation rates of +55.8 vs. +20.2 vs. -11.0 , respectively; $F=8.4$, d.f. $=2, p<0.001)$. Conversely, 44 children showed an increase in school breakfast participation and 14 of these children (32\%) showed an improvement in nutritional status. Children who showed improved nutrient intake 
reported a significantly greater decrease in symptoms of hunger on the CHI-C (mean change $=-1.4$ ) than children whose nutritional status remained the same $(-0.2)$, or those who reported a worsening of their nutritional status $(\mathrm{M}=+0.3$ [an increase in hunger]; $\mathrm{F}=13.4$, d.f. $=2, \mathrm{p}<$ 0.0001). Children who improved their nutritional intake showed significantly larger decreases (improvements in functioning) in their PSC-Y scores $(\mathrm{M}=-3.2)$, compared to children whose nutritional status remained the same $(\mathrm{M}=-2.0)$, or children whose nutritional intake category worsened $\left(\mathrm{M}=+1.9 ; \chi^{2}=5.2\right.$, d.f. $\left.=2, \mathrm{p}<0.01\right)$.

Of the four individual subjects examined, only changes in math grades were found to be significantly related to changes in nutrient intake $(F=3.3$, d.f. $=2, p<0.05)$. Children who improved their nutrient intake significantly decreased in the number of days in which they were absent $(\mathrm{M}=-4.4$ days $)$ in comparison to a smaller decrease in absences among children whose nutrient intake did not change $(\mathrm{M}=-1.7$ days) or children whose nutrient intake worsened $(\mathrm{M}=+3.0$ days absent; $\mathrm{F}=5.9$, d.f. $=2, p<0.01)$. The overall decrease in tardiness among those with increased breakfast participation failed to reach statistical significance, but was in the predicted direction.

\section{Discussion}

Although we have made significant progress in understanding and validating the negative impact of hunger [2, $3]$ and food insecurity in children in the USA $[1,4,15]$, the relationship between low nutrient intake, assessed by 24-hour food recall, and hunger and their relationship to psychosocial and academic functioning in children has not been well explored.

The definition of low nutrient intake used in this study is per se arbitrary and is based upon consumption of $\leq 50 \%$ of the recommended daily allowances of selected nutrients. There is no universally accepted definition of undernutrition that is linked to recommended intakes of nutrients. In many studies, $\leq 67 \%$ of the RDA for a nutrient is considered to be 'low'. We sought a lower cutoff point for a percentage of the RDA that might actually reflect undernutrition, although this remains to be tested. Children in this study who reported low nutrient intakes had lower GPAs and higher rates of absenteeism and tardiness than children from the same schools who reported higher levels of nutrient and energy intake. Students who reported low nutrient intakes had more symptoms of hunger and psychosocial problems (by both their own and their parents reports) than students with higher nutrient intakes. Perhaps even more importantly, students who increased their nutrient intakes after the start of a free school breakfast program were more likely to improve their nutrient intake status and academic and psychosocial functioning.

There are several limitations that need to be considered when interpreting the results of this study. First, the generalization of the study's findings may be limited since less than half of the potential subjects were actually enrolled in the study and since the sample size was relatively small and consisted primarily of low-income, African-American and Hispanic children from a single area of the country. However, similar rates of child hunger [1] and school breakfast intake [20] have been found in large national surveys. Second, the analyses of nutritional intake for the pre- and post-assessments were based upon a single 24-hour dietary recall for each child, which may not reflect actual nutrient intake over the entire study period. Finally, since breakfast consumption was not specifically examined as distinct from total daily intake, its actual contribution to study outcomes could not be determined.

These limitations notwithstanding, the significant outcomes found in this study indicate the need for further research investigating nutritional risk and its relationship to child academic, and psychosocial functioning, hunger, and breakfast eating patterns in larger, multi-site samples that allow for multiple assessments of dietary intake and child functioning over several time points. These outcomes have major implications for the school breakfast programs that are in place in many cities in the USA. Making breakfast free to all students irrespective of socioeconomic status offers the potential for improved nutrient intake, decreased hunger and improved academic and psychosocial performance. A continuation and expansion of free-to-all school breakfast programs appears warranted and should receive additional research attention.

\section{Acknowledgements}

The study was made possible through a grant from Project Bread/ The Walk for Hunger, Boston, Mass. The generous cooperation and collaboration of the Department of Food and Nutrition Services of the Boston Public Schools, and the participating teachers, students, and parents at the Dennis C. Haley School, the Sarah Greenwood School, and the Grover Cleveland School Middle School are gratefully acknowledged. 


\section{References}

1 Bickel G, Carlson S, Nord M: Household Food Security in the United States 1995-1998; Advanced Report. Alexandria/Va, Food and Nutrition Service, United States Department of Agriculture, 1999. Available at WWW.fns. usda.gov/oane/MENU/Published/FSP/FILES/ foodsec98.pdf.

2 Kleinman RE, Murphy JM, Little M, Pagano M, Wehler CA, Regal K, Jellinek MS: Hunger in children in the United States: Potential behavioral and emotional correlates. Pediatrics 1998;101:100-111.

3 Murphy JM, Wehler CA, Pagano ME, Little M, Kleinman RE, Jellinek MS: The relationship between hunger and psychosocial functioning in low income American Children. J Am Acad Child Adolesc Psychiatry 1998;37:163-170.

4 Alaimo K, Olson CM, Frongillo EA, Briefel RR: Food insufficiency, family income, and health in US preschool and school-aged children. Am J Public Health 2001;91:781-786.

5 Murphy JM, Pagano ME, Nachmani J, Sperling P, Kane S, Kleinman RE: The relationship of school breakfast to psychosocial and academic functioning: Cross-sectional and longitudinal observations in an inner-city school sample. Arch Pediatr Adolesc Med 1998;152: 899-907.

6 Friedman BJ, Hurd-Crixell SL: Nutrient intake of children eating school breakfast. J Am Diet Assoc 1999;99:219-221.

7 Nicklas TA, O'Neil CE, Berenson GS: Nutrient contribution of breakfast, secular trends, and the role of ready-to-eat cereals: A review of data from the Bogalusa Heart Study. Am J Clin Nutr 1998;67:S757-S763.
8 Nicklas TA, Bao W, Berenson GS: Nutrient contribution of the breakfast meal classified by source in 10-year-old children: Home versus school. School Food Service Research Review. 1993; 17:125-132.

9 Sampson AE, Dixit S, Meyers AF, Houser R Jr: The nutritional impact of breakfast consumption on the diets of inner-city African-American elementary school children. J Natl Med Assoc 1995;87:195-202.

10 Farris RP, Nicklas TA: Characterizing children's eating behavior; in Suskind RM, Suskind LL (eds): Textbook of Pediatric Nutrition, ed 2. New York, Raven Press, 1993, pp 505516

11 Nicklas TA, Forcier JE, Webber LS, Berenson GS: School lunch assessment as part of a 24hour dietary recall for children. J Am Diet Assoc 1991;91:711-713.

12 Food and Nutrition Board: Recommended Dietary Allowances, ed 10. Washington, National Academy of Sciences, 1989

13 Gong EJ, Heald FP: Diet, nutrition, and adolescence; in Modern Nutrition in Health and Disease. Philadelphia, Lea \& Febiger, 1994.

14 Serra-Majem L, Ribas L, Pérez-Rodrigo C, García-Closas R, Peña-Quintana L, Aranceta J: Determinants of nutrient intake among children and adolescents: Results from the enKid Study. Ann Nutr Metab 2002;46(suppl 1):3138
15 Wehler CA, Scott RI, Anderson JJ: The Community Childhood Hunger Identification Project: A model of domestic hunger - demonstration project in Seattle, Washington. J Nutr Educ 1992;24:29S-35S.

16 Bickel G, Andrews M, Klein B: Measuring food security in the United States: A supplement to the CPS; in Hall D, Stavrianos M (eds): Nutrition and Food Security in the Food Stamp Program. Alexandria/Va, US Department of Agriculture, Food and Consumer Service, 1996, pp 91-111.

17 Jellinek MS, Murphy JM, Little M, Pagano ME, Comer DM, Kelleher KJ: Use of the Pediatric Symptom Checklist to screen for psychosocial problems in pediatric primary care: A national feasibility study. Arch Pediatr Adolesc Med 1999;153:254-260.

18 Pagano ME, Cassidy LJ, Little M, Murphy JM, Jellinek MS: Identifying psychosocial dysfunction in school-age children: The Pediatric Symptom Checklist as a self-report measure. Psychol Schools 2000;37:91-106.

19 Gall G, Pagano ME, Desmond SM, Perrin JM, Murphy JM: Utility of psychosocial screening at a school-based health center. J School Health 2000;70:292-298.

20 Briefel R, Murphy M, Kung S, Devaney B: Universal-free school breakfast program evaluation design project. Review of the literature on breakfast and learning. Final report. Princeton/ NJ, Mathematica Policy Research, USDA Contract No 53-3198-7-006, Dec 1999. 